\title{
Challenges in the provision of community aged care in China
}

\author{
HUI YANG, COLETTE BROWNING, SHANE THOMAS
}

\section{Abstract}

Objective: Population ageing in China is a significant challenge for the Chinese government, the society and Chinese people. The dramatic process of population ageing together with social and economic diversity in China has created issues in the availability, equality and sustainability of social and financial support for older people. The aims of this review are to identify the social and economic challenges to the traditional caregiving system in China, and to examine possible solutions to improve the care of older people in China using the framework of ageing in place.

Methods: Electronic literature searches were conducted in May and June 2013 using PubMed, CNKI, and MEDLINE. Statistical data and reports were retrieved from the United Nations, the World Health Organisation, the World Bank and National Bureau of Statistics of China. Government policy documents were found through government websites and formal publications.

Results: Family-centred care for older people in China is recognised as a cultural tradition in the Chinese community. However, driven by large-scale social, political and economic changes, this model of caring for older people has dynamically changed over the last 50 years. Traditionally the family has been the most important source of social support for older people followed by neighbour support and support from friends. Today family obligations of caring are still centred in a cultural and practical context; however, support from family and children has weakened incrementally. Community-based aged services are absent in most areas, while older people and their families have to pay out-of-pocket expenses for non-residential services. There is a severe shortage of aged care or nursing home resources in China and those that exist are of low quality and expensive. The staff who work in these facilities rarely have any formal training in aged care. In addition, a market approach to the funding of residential aged care has the potential to create a moral hazard due to the poor regulatory control of aged care in China. While the building of residential aged care homes is seen as the solution to the care of older people in China, older people prefer to age in their own homes and expect the restoration of the family care tradition as well as more government support for them to "age in place". This approach has the potential to be more cost effective than expensive aged care facilities.

Conclusion: Given older people's preferences, ageing in place, with the provision of community services and family support, potentially provides a fair and financially viable approach to promote healthy ageing and supportive care in China. Further studies are required to identify 1) how ageing in place can be supported by a national strategy, 2) the financial arrangements required to fund such an approach, and 3) how to train high quality community-based professionals in both rural and ur-

School of Primary Health Care, Faculty of Medicine, Nursing and Health Sciences, Monash University, Victoria 3168, Australia

CORRESPONDING AUTHOR: Hui Yang

School of Primary Health Care, Faculty of Medicine, Nursing and Health Sciences, Monash University, Victoria 3168, Australia

hui.yang@monash.edu

Funding: This research received no specific grant from any funding agency in the public, commercial, or not-for-profit sectors. 
ban areas to support the care of older people.

Keywords: Population ageing, Healthy ageing, Ageing in place, Aged care, Community-based care, China

\section{Introduction}

China was formally labelled as an ageing country in the beginning of the 21 st century when the proportion of the population aged 65 years and over reached $7 \%$ of the total national population [1]. China's population is ageing rapidly. Based on the 2010 population census, $8.87 \%$ of the national population (near to 120 millions) are aged 65 years and over [2]. Population ageing in China is associated with improvement in infant and maternal health and the general health of the population, national economic development and improved public health policies, and the unique population policy (the one child policy) implemented in the 1970s [3]. As in other developed countries, population ageing in China is unprecedented, pervasive, and enduring and has profound implications for human society [4]. The phenomenon of population ageing challenges society to adapt, maximise health and functional capacity for older people, and improve their social participation and security.

Unlike Western countries that have faced challenges of population ageing in a time of relative economic prosperity, China's population ageing is occurring ahead of its economic development; it is 'old before rich'. This presents a challenge to its traditional forms of care and support for older people as traditional caregivers such as adult children are occupied with taking advantage of the economic boom [5]. The current health and aged care systems are also under pressure due to a large gap between demand and supply, as well as the dilemma for government in balancing the demands of market forces (for example, the growth in private aged care facilities), societal expectations and government responsibilities [6].

In this paper, we explore these challenges, through reviews of existing national statistical data, ageing studies and our selected qualitative studies. We then discuss the rationale for promoting community-based health and aged care approaches to promote ageing in place and healthy ageing.

\section{Methods}

Electronic literature searches were conducted from May to June 2013 using PubMed, CNKI, and MEDLINE. Statistical reports and policy documents were retrieved from websites of the United Nations[7], the World Health Organisation[8], the World Bank[9], National Bureau of Statistics $[1,2,10]$ and related government departments of China[3]. Findings from empirical studies were extracted from the National Urban and Rural Older People Longitudinal Survey [11-13], the Chinese Family Panel Study $[14,15]$, and the Cross-Cultural Conceptualizations of Ageing Study [16].

The Findings of empirical studies of the National Urban and Rural Older People Longitudinal Survey (2000, 2006 and 2010) were also extracted. This nationwide program was sponsored by the Central Government of China and consisted of interviews with 20,000 Chinese urban and rural residents aged 60 years or over. Another survey we consulted was the Chinese Family Panel Study $(2009,2011)$ conducted by Peking University China in collaboration with USA and Australian experts. Qualitative findings of the Cross-Cultural Conceptualisations of Healthy Ageing study conducted by Monash University in collaboration with Peking University were also included. The study was conducted through in-depth interviews and focus group discussions in the cities of Beijing, Guilin and Melbourne during 2009 - 2010.

\section{Results}

\section{Population ageing in China}

There are a number of reports in China that examine population ageing. The scale of population ageing in China in terms of absolute numbers and the rate of increase in population ageing is larger than in developed countries. However there are some similarities with developed countries. Figure 1 demonstrates a comparison between China and Australia [17]. We have chosen Australia as a reference as it has a well-developed aged care system and later we will reflect on Australia's response to population ageing. As shown in Figure 1, by 2030 China will have a similar population ageing 


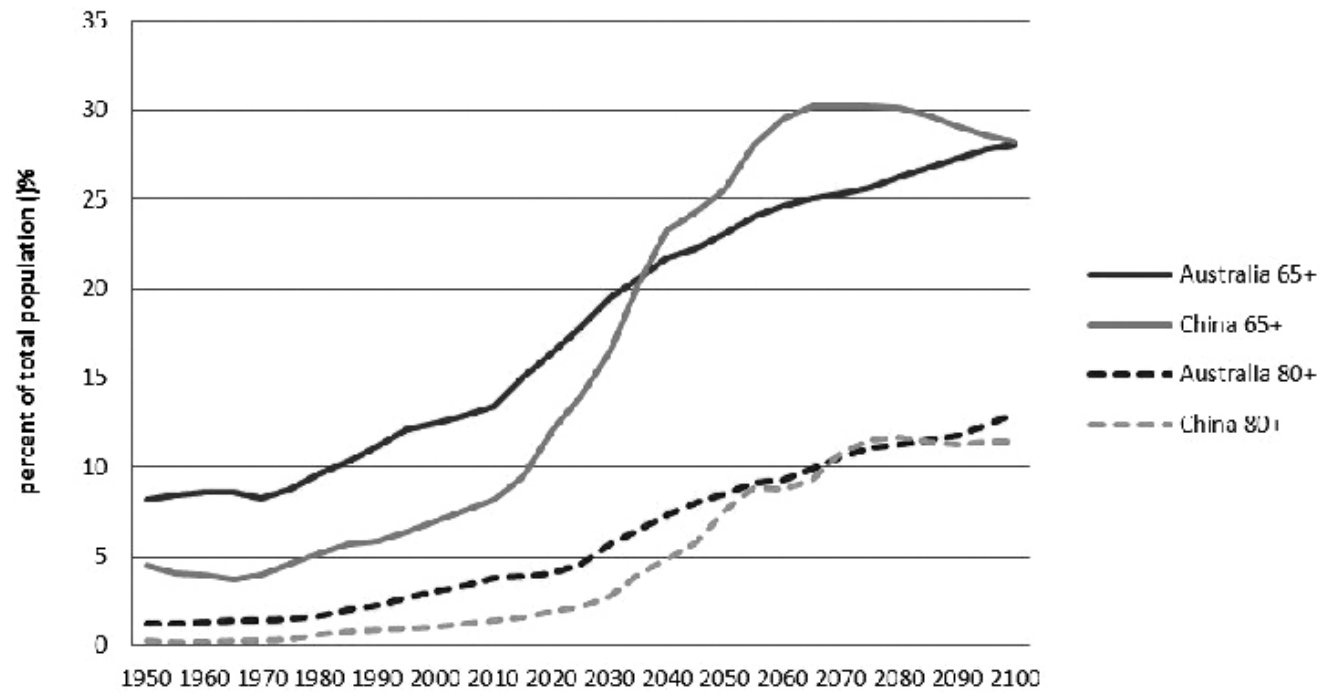

Figure1 Percent of old people in national population, China and Australia

profile as Australia, with approximately $22 \%$ of the population aged 65 years and over. However, over the 70 years between 2030 and 2100 the proportion of China's aged population will grow more rapidly than that in Australia, reaching $30 \%$. By 2100 the countries will again have similar population ageing profiles.

It would be naïve, however, to focus on these overall population trends of China when there is much diversity across the country. In a populous country like China with a vast territory, diversity in population ageing can be found across regions as well as social and economic groups. Comparing the developed areas of China (the eastern and coastal areas), developing areas (central plains and agricultural areas), and least developed areas (western and frontier areas), the proportion of older people decreases in parallel with increases in GDP per capita $[2,18]$. In the 'dual society' (rural vs urban), rural areas are ageing faster than urban areas, due to the internal migration of younger rural people to large cities [6], and reduced fertility in rural areas [19]. As in other countries, China's gender differences in population ageing is also significant; in 2010, life expectancy was 74.8 years in the general population, 72.4 years for men, and 77.4 years for women [20].

Like other countries that have experienced population ageing, China is grappling with the problem of how to support and care for its ageing population and promote healthy and active ageing, a key policy approach adopted in many western countries [21, 22]. To understand the context of current approaches, in the next section we examine the changes in the care of older people in China from the first half of the 20th century through today.

\section{Evolution of caring older people in China}

The form of economic production is the foundation of the social and political structures of a country [23, 24]. The traditional Chinese economy is based on rural family based enterprises. Traditionally, Chinese people inhabit a 'familycentred' society. Linguistically, the 'country' in Mandarin (国家, Guo Jia) refers to 'a collection of families'. This perception is attributed to a long history of agricultural production in China, in which, the family (家, Jia) - a concept of 'living and eating together' - is the basic unit of production and forms the key cell of society. Under this tradition, the family social structure is a major source for caring for older people in China [25].

Pre-1960s

Before the 1960s, family support from children and/or grandchildren was the main and core form of caring for older people [25-27]. Specifically, female members -- wife, daughter, daughterin-law or grand-daughter-in-law -provided daily care for the older person [28, 29], while male members -- son or grandson -- were responsible for financial support of their aged parents or grandparents. That adult children should provide 'feedback benefits' to older parents was socially agreed as a fundamental social norm: parents of working age contributed to bringing up their children and then naturally they should be cared for by their children when they became old and could not work anymore. In the context of self-sufficiency of agricultural China, the family was the major or only source of support for older people; and the younger generation was expected to fulfill their family obligations $[30$, 
31]. The support was based on social fairness, social stability and strong intergenerational relationships. Philosophers such as Confucius and Mencius advocated the good treatment of elders and filial piety. Traditional beliefs include 'having children is important for a happy old age' and 'sons will care for you in old age'.

Support from neighbours and relatives was complementary to family support [32], or the second line of security for older people. Firstly, neighbours shared the same natural resources (land, water or means of production) in farming communities. Secondly, adult children (especially sons), and close or distant relatives tended to live in the same village. Therefore neighbours or relatives were considered a 'kinship family' or extended family. It was expected that the extended family could support older people, as a traditional belief is to 'love other's elders as your own'. However, compared to family obligations, the neighbours'/relatives' obligations were considered weaker. Neighbours would assist older people if the family was facing difficulties, emergencies or disasters [33].

Meanwhile, religious and/or moral obligations required citizens to provide short term assistance to older people in times of great need, on special occasions, or if they were poor [34]. As with other religious centers, food was provided to the very poor older people at the Chinese Buddhist temple [35]. Rich people or landlords also provided support on specific occasions such as Chinese New Year. Their kindness stemmed from the desire to assist people as if they were 'their children', and in doing so they would improve their image and not 'lose face.'

$1960 s-1980 s$

A revolutionary change in the care of older people occurred during the $1960 \mathrm{~s}$ and 1970s after the Chinese 'land reform', 'people's commune movement', and the 'cultural revolution'. Communism and collectivism changed the family-based production method, which impacted the traditional family care model. Family support for older people was still central but it became weaker in its effectiveness [36]. At the same time, the collective force became a powerful source of community support, especially financial support, where collective funds provided food and living necessities to villagers. Collective funds also supported free medical care through 'barefoot doctors', and provided housing for older people who did not have income, children and caregivers, and those with disabilities.

Religion-oriented support was forbidden during this period of time, however neighbour (comrade), relative, and moral support still existed. Although the 'one child family planning policy' was implemented, the effect of the policy on the care of older people was not evident during this period.

$1980 s-2000 s$

This was the era of the reformist Deng Xiaoping whose aim was to open China to the world and lead China into a market economy. Collective economic approaches collapsed and farmers returned to a family-based economy. While this apparently gave more power to the family, the gap between the rich and poor became wider. About $10 \%$ of Chinese people, mainly young farmers, migrated to the cities seeking work opportunities and leaving their older parents behind in the village. As a consequence of the collective fund approach collapsing, rural residents lost their basic and free medical care and aged care services. In urban settings, many state-owned enterprises (SOEs) collapsed and urban workers were forced into unemployment. In the context of market-driven environment, governments were unlikely to fund social security programs because the social programs did not contribute to productive efficiency. The cost of this major social transition was that older people had extremely limited access to services. Social fairness was damaged, and the tradition of caring had been marginalized [37]. Human kindness and family love became 'pale and weak' as the population prioritised financial gains.

Post $2000_{s}$

In the new century, family support and financial assistance to older people became weaker - due to the demographic effect of the one child policy and internal population migration. At the same time Chinese social pensions and retirement insurance were developing in both urban and rural areas.

Family structure changed dramatically over this period $[24,25,36]$. The proportion of 'empty nesters' in people aged 60 years or older increased from $42 \%$ in 2000 to $54 \%$ in 2010 , while in rural areas, the rates were $38 \%$ and $46 \%$ in 2000 and 2010, respectively [11, 13].

In this period, the Hu-Wen government (2003 - 2013) redirected national policy from encouraging 'becoming 
as rich as you can' to 'becoming richer together'. Social security schemes to improve equality and fairness were developed or strengthened. Based on the China Urban and Rural Older People Longitudinal Study [13], the proportion of urban older people who had retirement pensions in 2010 was $85 \%$, higher than in $2000(69 \%)$ and 2006 (78\%). The proportion of rural older people who had aged care insurance in 2010 was $35 \%$, significantly higher than in $2000(3 \%)$ and in 2006 (5\%). While there were increases in the proportion of older people with pensions and aged care insurance over the period, the financial resources gap between rural and urban areas is still evident.

\section{Social transitions and changes to family-based care \\ Threats to family-based care}

The 'one child policy' has put a strain on family based care. Chinese family size has become smaller, especially from the effect of the one child family policy [36, 38]. There has been a reduction in the number of traditional caregivers (daughter-in-law or grand-daughter-in-law), and their availability to care for their parents has been weakened due to the demands of working and earning money. The '8-4-2-1 syndrome' (a busy young couple has insufficient ability to provide care to one child, four patients and eight grandparents) has occurred both in rural and urban China.

The number of multi-generation families has declined. Most young people (before and/or after marriage) desire to live independently of their parents [36]. Older people also wish for their adult children to live independently of them in order to prevent conflict between the generations and to reduce the chances of the older person 'becoming a burden'. Physical or geographic barriers are also significant in influencing the tradition of family-based care. Urban older people who live in residential apartments have less opportunity for being cared for by other family members. The rural younger generations leave their villages to find work in the cities and leave their young children in the care of their older parents in the village.

This major social transition started in the 1980s and has caused a narrowing of the concept of family. In China, family today means a nuclear family with dependents often living away from the family breadwinner. While family-based care is still very common today, it is under threat from the 'one child policy', urbanization and internal migration.

An alternative to family based care (1) - self care

Older Chinese people now recognise that they cannot rely totally on their families for care and support. Self care and the care of one's spouse is accepted as a consequence of the current economic climate. Researchers of Monash University and Peking University jointly conducted a study of cultural conceptualisations of healthy ageing in China and Australia [39]. This qualitative study provided insights into the perception of Chinese older people about traditional care and alternatives. Below are some quotes from our interviews with older people.

Others can't take care of me. I wish for my children to come very much, but my children don't have time. My son is very tired from work. And, he also has no strength to take care of me. I have to take care of myself. But I need to help with the grand children, get up at 5 o'clock to take them to school. We not only have to help ourselves' but also to help our grandson, granddaughter .... (Beijing man aged 82 years)

We do think that physical health is the most important. Except that, also, we should have "Laodi"(老底), "Laowo" (老窝) and “Laoban”(老伴). “Laodi” means having some money. For example, an old man who lives in a rural area should also have some income. "Laowo" means having a dwelling to live in. A senior also needs a "Laoban" (a partner), or else he would be lonely. If an old man or woman does not have a "Laoban", he or she will feel very lonely. It can be said that this upsets him or her significantly. Therefore, apart from good health, we also need the three Laos. Furthermore, we need a cozy home and welfare. We need to have ease of mind and a healthy diet. We should insist on exercising and guarding ourselves against diseases. (Guilin man, teacher aged 76)

Therefore, older people in China have understood that they need to stay healthy and independent in old age as they cannot rely on their children for their care.

An alternative to family based care (2) formal aged care

Formal aged care in China has become more common as older people begin to accept that they need to find and pay for care resources outside the family. 
In Australia formal aged care includes community care (services to the home, including meals, home help, and nursing services) and residential aged care (nursing homes) [40]. These are heavily subsidised through the taxation system. However, community care approaches are virtually non-existed in China [4143].

The provision of community (inhome) care services for older people is rare in China. The term 'community' in China is identified administratively as a geographic area of $100-300$ thousand residents in an area. This equates to a collection of suburbs in an urban setting or a township in a rural area. In China within government settings, the residents or villager committee, a self-governance body, oversees the livelihood of the local people. Both urban and rural residents committees are self-funded and have limited financial support from local and central government. So these committees often lack the resources to care for the older residents. The current social security programs for older people, including basic medical care insurance or aged pension programs, are not accredited to fund community-based services, such as home help or meals services, for older people. Therefore, residents and villagers have to use their own personal financial resources for aged care, higher level healthcare, and basic services such as 'meals on wheels' (food delivered to the home), personal care such as bathing, and general home help. In addition, government and state enterprises provide a specific retirement package to their retirees. This approach is worsening the issues of equality and accessibility as people working outside these enterprises cannot access these packages.

The main alternative to family and self-care in China is self-funded aged care accommodation/homes. Based on the China Urban and Rural Older People Longitudinal Study [13], 799 million older people in China are fully disabled (154 million in urban and 645 million in rural areas) and 1,460 million older people are partially disabled (260 million and 1,200 million in urban and rural areas, respectively). Overall, China needed 22.6 million beds in aged care facilities in 2010, based on estimations from this survey. However, there were only 1.48 million aged care beds available in the same year [13]. In other words, 93.4\% of needs could not be satisfied.

Most (two thirds) existing aged care/ nursing homes are owned and operated by the local government in urban settings or by a collective committee in rural settings. The rest (one-third) are operated by the private sector. For instance, in a recent analysis of the availability of age care beds in Beijing, about 400 aged care homes were identified and 55,809 beds were occupied. Of these, 24,525 beds were provided by the private sector [44].

The provision of aged care homes is seen as a growing market for investment aimed at the richer middle class in China. However, the quality of aged care is questionable, and the market is poorly regulated. Based on a Beijing government report [45], the majority of aged care beds are for 'low care', which includes accommodation and personal assistance, but excludes medical and nursing care. The cost of low care is around 2,500 - 3,000 Yuan/month in the private market. However, many older people feel that most of the current aged care facilities are 'unlivable' (i.e., they are unsatisfied with the material conditions of the facilities and the poor services) and expensive. It is estimated that the cost of high quality, 'livable' aged care facilities is in the order of 5,000 10,000 Yuan per month. Given that the average aged pension is 2,500 Yuan/ month for urban retirees and 400 Yuan/ month for rural older people, livable aged care is obviously unaffordable for the majority of older people in China. Based on the same report in Beijing, older people are willing to pay $40 \%$ of their pension for aged care. This equates to 1,016 Yuan/month in urban settings and 172 Yuan/month in rural settings. The following quote is from a participant in our Cultural Conceptualizations of Healthy Ageing study:

We all know, $Y$ i-Fu is the best aged care home in Beijing ... government owned and good condition and its price is lower than luxury homes. You know, about 9,000 older fellows in front of me in the waiting list. I was told to get a bed there at least ten years later. I will game over before that [get in]... Anyway I cannot get in, because the staff said I am too disabled... too many diseases. I guess they do not like me, they like healthy elderly... for less caring work. For my situation, they will charge more money. This Home costs 5,000 Yuan a month... for healthy elderly. I cannot do it because I just have 2,000 Yuan pension [a month]. I have to stay in my house, and love to stay in my house. EV- 
ery week, I wait...wait... wait my son see me on Saturday. (Beijing woman, aged 72)

A major quality indicator of aged care is the quality and experience of the staff and managers of the facility. In 2012, Xu [46] conducted a survey in 339 Beijing aged care facilities and found the average age of the staff in aged care was 44 years old, i.e. comparing with other industries, the aged care workforce is older. In this labor-intensive industry, two thirds $(66.5 \%)$ of staff did not have any vocational training or any formal education higher than year 10 (secondary school in China). Twenty-six percent of staff completed their high school (12 years of education) or technical school (10 years of education plus 2 years technical training), 5.5\% of them had a diploma of junior college, and $1.2 \%$ of them completed undergraduate education. The last two groups were found only in a few public aged care facilities. Few staff received formal aged care training.

Given the shortage, high expense, and low quality of current formal aged care in China, plus the desire under traditional cultural values to 'age at home', older people have significantly changed their attitudes towards formal aged care. Based on data from the China Urban and Rural Older People Longitudinal Study [13], the views of older people regarding living in aged care homes has changed over the last 10 years. According to this study (conducted by China Research Centre on Ageing, CRCA), the percentage of urban older people who were willing to move to an aged care facility dropped from $18.6 \%$ in 2000 to $11.3 \%$ in 2010 ; while the proportion of rural Chinese willing to move to an aged care facility also dropped from $15.2 \%$ to $12.5 \%$.

Income of older people and affordability for aged care

Income level and distribution

China has experienced significant economic development over the last three decades. For the general population, the urban resident annual disposable income reached 1,000 Yuan in 1987, and then accelerated to 19,000 Yuan per year in 2010 and 24,565 Yuan per year in 2012 [10]. For rural residents, their net income also increased but at a relatively slower rate compared to urban residents, and the overall net income for rural residents was lower than urban residents. In 2012, rural net income was 6,977 Yuan, as reported by the National Bureau of Statistics. The income gap between rural and urban residents in the general population became wider in the last three decades [37]. In the 1980s, according to the National Bureau of Statistics, the income of urban residents was 1.8 -2.3 times as much as that of rural residents; the gap was 3.3 times in 2009 and 3.5 times in 2012. It was reported that the GINI coefficient reached 0.474 in 2012 [47], while the figure was highest at 0.491 in 2008. For older people, the urban-rural gap was much wider (a 3.8 -4.4 times difference). Considering the difference in social security coverage between urban and rural residents, urban older people have 6.0 times as much income and social benefits as rural older people.
Overall, the income distribution among older people is uneven. Based on the Chinese Family Panel Study (CFPS 2010, conducted by Peking University, and academically supported by US and Australian colleagues) [14], two thirds of older Chinese people had an annual income lower than 2,500 Yuan (about 1.1 A \$ per day). A higher percentage of low income older people was found in lower SES areas. Despite the overall economy improving, there were more people living on low incomes. For instance, in Shanghai $50 \%$ of older people had incomes less than 2,500 Yuan, and the percentage in Guansu was $80 \%$. Older women had a significant disadvantage -$77.8 \%$ of older Chinese women had an income lower than 2,500 Yuan per year; while the percentage of older Chinese men with a comparable low income was $56.6 \%$. It was found that a higher proportion of rural older people (72.6\%) had an annual income less than 2,500 Yuan, compared to the figure of $54.7 \%$ for urban older people.

Income sources for older people

There are three major sources of income for older people, based on the China Population Census 2010: working income, retirement pension, and children's support [2]. In 2010, based on the Census, $29.1 \%$ of older people (60 years or over) claimed they generated income from work $(36.6 \%$ of older men and $21.9 \%$ of older women; $6.6 \%$ in urban settings and $41.2 \%$ in rural settings). The second source was retirement pension (including superannuation, government pension and/or retirement allowance). Based on the Census, 24\% of older people reported that they received a pension 
(28.9\% of older men and $19.6 \%$ of older women; $66.3 \%$ in urban settings and $4.6 \%$ in rural settings). The third source was the traditional financial assistance from children. $40.7 \%$ of older people relied on their children's financial support (28.2\% of older men and $52.6 \%$ of older women; $22.4 \%$ in urban settings and $47.7 \%$ in rural settings).

The data discussed above provide a clear picture that family/children financial support was still the main source of financial support for older people even though that support has reduced in the last three decades. The good news for urban retirees is that the pension has provided significant coverage in contrast to their rural counterparts. However, older women are disadvantaged in terms of pension income and rely more on family support than older men do.

\section{Discussion}

\section{Challenges in China}

Population ageing in China is described as 'getting old before getting rich'. This means that unlike in other countries such as Japan and Australia, government and individuals may not have the resources to fund the services needed by older people. Seniors in China have been also characterized as a 'giant burden' due to the enormous absolute numbers of older people, and the growing gaps in financial resources between older rural and urban dwellers, between men and women, and between social classes. After 30 years of a market economy in China, population ageing has the potential to provide new markets for businesses who wish to profit from this demographic transition, but older Chinese people and their families are growing sensitive to the provision of quality services and concerns about how they will pay for these services.

For the Chinese government, the difficulties in funding services for an aging population arise from a shrinking labour force, and hence a higher old age dependency ratio, that impacts on national revenue (taxation). More importantly the new government has understood the risk and opportunity of 'getting betteroff fairly and equally', and the difficult identification of the trade-off between government influences and market forces. Social security for older people (and of course for the nation) has been quickly expanded in recent decades. However, the system is not mature enough for the effective protection across all groups and does not provide equal opportunity for 'happy ageing' for urban and rural people, the rich and poor, and for men and women. Insufficient government financial support for older people has forced them and their children to seek services that they pay for personally, or in many cases has meant that they cannot afford expensive aged care services.

As in other countries, aged care facilities or residential aged care is the most expensive form of care for older people. As discussed, few Chinese older people and their children can afford the quality of aged care equivalent to their expectations and in many cases the affordable facilities are of a poor standard and unregulated. In addition, the infrastructure for aged care requires a long term and large investment. Firstly, large numbers of facilities need to be built to respond to the significant demand; sec- ondly, large investments in workforce training and sustainability need to be strategically considered; and thirdly, 'soft investments' such as regulation, funding policies, accreditation of facilities, and quality improvement need to be addressed. For China, most of these three areas are in the initial stage of development.

Ageing in Place: a strategic approach

In Australia, "Ageing in Place" is a key policy approach for healthy ageing [40]. The central idea is that older people should be supported to age in their own homes and communities. To achieve Ageing in Place, community care packages (food, housework, nursing services etc.) are provided to older people. Importantly, Ageing in Place requires that care and support services are linked to the places where older people prefer to live.

The aims of an Ageing in Place policy is to encourage support from the family and at the same time provide community-based care to those in most need. It is assumed that this is more cost effective than residential aged care, and hence will deliver financial sustainability across the system and in addition will deliver higher satisfaction to older people and their family as it addresses the older person's desire to age at home in a familiar environment.

This approach is consistent with experiences in China and other countries under the medical and mental health system reforms. For instance, the Chinese health sector reform is focusing on shifting medical care services from tertiary 
hospital-based services to communitybased primary care services [48-50]. In most developed countries, mental health services have been deinstitutionalized from psychiatric institutions to community-based mental health services that include general practitioners in shared mental health service delivery [51].

The debate about the provision of aged care services in China comes from two directions:

- The desire to provide commercial goods from the private sector for richer citizens who are the minority in China and where residential aged care is seen as ideal for productive efficiency to achieve the lowest cost and with the highest profit to industry, or

- The desire to provide public goods from the public sector for everyone with additional support to urban and rural disadvantaged groups and where home/ community-based care is the best choice for allocative efficiency. Different from productive efficiency, allocative efficiency aims to achieve optimal distribution of aged care services while taking into account the preferences and needs of older people. Output is achieved with the price equal to marginal utility or the cost of service production.

In addition, and possibly more important, the type of services and the way in which they are delivered should be the person's choice. While the push in China is to build aged care homes to accommodate its burgeoning older population, like older citizens in other countries, the older person in China has a preference to age in place in their own home and community.

Ageing in Place policies do not re- duce the opportunity for new businesses. There is a growing market in China for home services for older people. In most countries there have been successful government, private, and non-profit mixed systems, and the market plays a strong role in the types of services offered. Governments in China need to oversee the governance and regulation of aged care services that emphasize equality and sustainability through ageing in place. In addition, governments need to provide standards for the industry and put in place quality frameworks.

Further studies are required to identify how Ageing in Place can be supported by a Chinese national strategy, central and local financial arrangements, families, and the wider community. Family function restoration initiatives need to be explored. For instance, the effects of recent Chinese legislation that requires children to regularly contact and support older parents [52]. For either community-based or residential aged care services, trained staff in both rural and urban areas are critical to improve the quality of aged care in China. The training programs should be carefully designed, monitored and evaluated.

In summary, population ageing is one of the greatest challenges to the society this century. To combat the challenge, we need to develop communitybased aged care for older people in accessible, cost-effective and sustainable ways.

\section{Acknowledgement}

Appreciation is expressed to Professor Zeqi Qiu and Professor Tuohong Zhang of Peking University, for their efforts on the studies Cross-cultural Conceptualisations of Healthy Ageing and the Chinese Family Panel Study, as well as for their suggestions about the article; and to Dr Kaiti Zhang of the China Research Centre on Ageing, and to many Chinese collaborators who assisted in our healthy ageing studies in China. We also want to express our appreciation to Professor Kenneth Kushner and Doctor Melissa Stiles in helping us reviewing and editing this article.

\section{Note}

Parts of content of this article were presented in a symposium at the World Health Summit 2013 Singapore and in a symposium of the 20th World Congress of Gerontology and Geriatrics Seoul 2013.

\section{Conflict of interest}

The authors declare no conflict of interest.

\section{References}

1. National Bureau of Statistics of China. Report of Fifth National Population Census 2000. Beijing: National Bureau of Statistics of China; 2001.

2. National Bureau of Statistics of China. Report of Sixth China Population Census 2010. Beijing: National Bureau of Statistics of China; 2011.

3. National Family Planning and Population Committee. National Report of Population and Development. Beijing: National Family Planning and Popualtion Committee; 2002.

4. World Health Organization. Good health addes life to years: Global brief for World Health Day. Geneva: World Health Organization; 2012.

5. Jackson R, Nakashima K, Howe N, Zhou J. China's Long March to Retirement Reform: the Graying of the 
Middle Kingdom Revisited. Washington DC: Centre for Statistics and International Studies; 2009.

6. Joseph AE, Phillips DR. Ageing in Rural China: Impacts of Increasing Diversity in Family abnd Community Resources. Journal of Cross-Cultural Gerontology 1999; 14 (2): 153-168.

7. United Nations Department of Economic and Social Affaires Population Division Population Estimates and Projection Section. World Population Prospects the 2012 revision. New York: Unitied Nation; 2013.

8. World Health Organization. World Health Statistics, Geneva: WHO; 2012.

9. World Bank. Total health expenditure as percentage of GDP. World Bank; 2012.

10. National Bureau of Statistics of China. National Economic and Social Development Report 2012. Beijing: National Bureau of Statistics of China; 2013.

11. China Research Centre of Ageing. China urban and rural older people longitudinal study 2000. Beijing: China Research Centre of Ageing; 2002.

12. China Research Centre of Ageing. China urban and rural older people longitudinal study 2006. Beijing: China Research Centre of Ageing; 2007.

13. China Research Centre of Ageing. China urban and rural older people longitudinal study 2010. Beijing: China Research Centre of Ageing; 2011.

14. Institute of Social Science Survey of Peking University. Chinese Family Dynamics 2011: report of China family panel study. Beijing: Institute of Social Science Survey of Peking University; 2011.

15. Institute of Social Science Survey of Peking University, Chinese Family Dynamics 2009: report of China family panel study. Beijing: Institute of Social Science Survey of Peking University; 2009.

16. Browning C, Qiu Z, Zhang T, Sharifian F, Yang H, Thomas S. How elderly conceptualise successful and healthy ageing. Journal of Chinese General Practice 2007; 10(15): 1226-1228.

17. Browning $\mathrm{C}$, Kendig $\mathrm{H}$, Thomas $\mathrm{S}$, Yang H. Healthy ageing in Australia: Policy responses and research opportunities. Journal of Chinese General Practice 2006; 9(19): 1575-1578.

18. National Bureau of Statistics of China. Gross Domestic Product. Beijing: National Bureau of Statistics of China; 2012.

19. Harrell S, Wang Y, Han H, Santos GD, Zhou Y. Fertility decline in rural China: a comparative analysis. Journal of family history 2011; 36(1): 15-36.

20. SN A. Why Women Live Longer than Men: Sex differences in Longevity. Gend Med 2006; June 3(2): 79-92.

21. World Health Organization. Policies and priority interventions for healthy ageing. Copenhagen: WHO Regional Office for Europe; 2012.

22. Australian Government. Living longer, Living better. Canberra: Department of Health and Ageing; 2012.

23. Bourguignon F. The Effect of Economic Growth on Social Structures in Handbook of Economic Growth. New York: Elsevier; 2005: 1701-1747.

24. Granovetter M. The Impact of Social Structure on Economic Outcomes. Journal of Economic Perspectives 2005; 19(1): 33-50.

25. Hare-Mustin RT, Hare SE. Family Change and the Concept of Motherhood in China. Journal of Family Issues 1986; 7: 67-82.

26. N G. Daughter-in-law as caregivers: how and why do they come to care? J Women Ageing 1999; 11(1): 85-102.

27. Woo J, Kwok T, Sze F, Yuan H. Ageing in China: health and social consequences and resonses. International Journal of Epidemology 2002; 31(4): 772-775.

28. NL C, K K. The Gendered nature of failial piety - a study among Chinese Canadians. J Cross Cult Gerontol 2007; 22(1): 29-45.

29. Holroyd E. Developing a cultural model of cargiving obligatons for elderly Chinee wives. West J Nurs Res 2005; 27(4): 437-456.

30. Lei X, Giles J, Hu Y, Park A, Strauss J, Zhao Y. Patterns and Correlates of Intergenerational Nontime Transfers: Evidence from CHARLS, in Smith JP, Majmundar M, Editors. Aging in Asia: Findings from new and emerging data initiatives. Washington DC: The National Academes Press;2012.

31. Fuligni A, Zhang W. Attitudes toward family obligation among adolescents in contemporary urban and rural China. Child Dev 2004; 75(1): 180-192.

32. Chen Y, Hicks A, While A. Loneliness and social support of older people in China: a systematic literature review. Health Soc Care Community 2013; May 28: Epub ahead of print

33. Yu Y. Community autonomous governance and government function restructuring. Beijing: China Social Science Publisher; 2005

34. Yang Q, Fan L. Religion and Ritual in Chinese Society: a Study of Contempirary Social Functions of Religion and Some of their Historical Factors. Shanghai: Shanghai People's Publisher; 2007

35. Zeng Y, Gu D, George L. Association of religious participation with mortality among Chinese old adults. Res Aging 2011; 33(1): 51-83.

36. China Population Headlines. The change of family size and structure in China. China Population Headlines 1992; (1): 2.

37. Gao Q. The Chinese social benefit system in transition: reforms and impacts on income unequality. Ann N Acad Sci 2008; (1136): 342-347.

38. Qujian D, Hesketh T. Family size, fertility preferences, and sex ratio in China in the era of the one child family policy: results from national family planning and reproductive health survey. BMJ 2006; 333(7564): 371-373.

39. Browning C, Qiu Z, Zhang T, Sharifian 
F, Yang H, Thomas S. Cross Cultural Conceptualisations of Successful and Healthy Ageing: Australia and China. Chinese General Practice 2007; 10(15): 1228-1231.

40. Australian Government Productivity Commission. Caring for older Australians: Productivity Commission Inquiry Report. Canberra: Productivity Commission; 2011

41. Fang Z, Liu C, Guan X, Mor V. China's rapidly aging population creates policy challenges in shaping a viable longterm care system. Health Affairs 2012; 31(12): 2764-2773.

42. Wu B, Carter M, Goins R, Cheng C. Emerging services for communitybased long-term care in urban China: a systematic analysis of Shanghai's community-based agencies. J Aging Soc Policy 2005; 17(4): 37-60.

43. Zhang $T$, Chen Y. Meeting the needs of elderly people in China: community health care is a good idea but unsatisfactorily implemented. BMJ 2006; 333(7564): 363-364.

44. Office of National Ageing Committee of China. Expereince of ageing services in selected provinces of China in 2009. 2009 [cited 2013 June 12]; Available from: http://www.cncaprc.gov.cn/ zhengce/4114.jhtml.

45. Zhao J. Beijing aged care facilities: too expensive to live with. China Economic Weekly 2012 [cited 2013 June 14]; Available from: http://finance.people. com.cn/n/2012/0710/c1004-18480420. html.

46. Xu X. Current condition and policy analysis of aged care facility in Beijing 2012. Jilin University; 2012.

47. Ma J. Chinese Government firstly released GINI coefficient 2003 - 2012. 2013; Available from: http://news.163.
com/13/0118/11/8LGH1BBF00014JB. html.

48. Bloom G, Xingyuan G. Health sector reform: lessons fro China. Soc Sci Med 1997; 45(3): 351-360.

49. Wang C, Rao K, Wu S, Liu Q. Health care in China: improvement, challengesm, and reform. Chest 2013; 143(2): 524-531.

50. Ho L. Market reforms and China's health care system. Soc Sci Med 1995; 41(8): 1965-1972.

51. Blashki G, Judd F, Piterman L. General Practice Psychiatry. Canberra: McGraw Hill; 2011.

52. China National People's Congress. Law for Protecting Rights of Older People 1996 (amended 2013). Beijing:N.P.s. Congress; 2013. om/13/0118/11/8LGH1BBF00014JB6. html.

\section{HYPERTENSION}

This quality standard defines clinical best practice within this topic area. It provides specific, concise quality statements, measures and audience descriptors to provide the public, health and social care professionals, commissioners and service providers with definitions of high-quality care.

This quality standard covers the management of primary hypertension in adults, including diagnosis and investigations, treatment to reduce risk of cardiovascular disease, monitoring of treatment efficacy, and specialist referral.

(Source: NICE Quality standards, QS28, March 2013; available at http://guidance.nice.org.uk/QS28 ) 